\title{
Percepção do uso de jogos integrados ao LMS Amadeus
}

\author{
Rodrigo Lins Rodrigues ${ }^{1,2}$, Paulo A. R. Perris ${ }^{2}$, Alex Sandro Gomes ${ }^{2}$ \\ ${ }^{1}$ Departamento de Educação - Universidade Federal Rural de Pernambuco \\ ${ }^{2}$ Centro de Informática - Universidade Federal de Pernambuco \\ rlr@ded.ufrpe.br, parp@cin.ufpe.br, asg@cin.ufpe.br
}

\begin{abstract}
One of the identified reasons for not using games in the learning process may meet the requirement that students and teachers have to realize the group's activities, a need that is not exploited by the LMS environments currently available on the market. In order to increase the student motivation level and to explore the possibility of provide perception to the group activity when playing, the current work is based on the design and development of an artifact allowing integration of games with the LMS Amadeus. To achieve this purpose we use the literature of Human-Computer Interaction, specifically the interaction design method.
\end{abstract}

Resumo. Uma das razões identificadas, para a não utilização de jogos no processo de ensino/aprendizagem pode corresponder à necessidade que os alunos e professores têm em perceber as atividades do grupo, necessidade esta que não é explorada pelos ambientes de LMS atualmente disponíveis no mercado. Com a finalidade de aumentar o grau de motivação dos alunos e explorar as possibilidades de dar percepção para a atividade do grupo ao jogar, o contexto desta pesquisa baseia-se na concepção e criação de um artefato para a integração de jogos ao LMS Amadeus. Para atingir o objetivo proposto, utilizamos a literatura de Interação Humano-computador, especificadamente o método de design de interação.

\section{Introdução}

Para apoiar atividades de formação e treinamentos antes tradicionalmente presenciais, diversos Ambientes Virtuais de Aprendizagem (AVA) vêm sendo continuamente desenvolvidos, testados e aplicados em cursos à distância. Nesses ambientes de ensino é importante que a aprendizagem seja envolvente e motivadora para os estudantes (Soares, Serra, Oliveira, \& Barroso, 2001).

Nestes ambientes, o aprendizado colaborativo é favorecido pela percepção que os usuários têm do ambiente e das atividades do grupo. A percepção é considerada um recurso de interação que pode contribuir para o desenvolvimento de usuários de ambientes de EAD. A percepção mútua da presença e das ações de usuários distantes representa um elemento de particular importância nestas atividades. Neste sentido, conceber AVA que atendam estas especificidades de prover a percepção de atividades práticas em grupo com a utilização de jogos, na maior parte das vezes, torna-se um grande esforço de reconstrução de ferramentas que já foram desenvolvidas e consolidadas. Por outro lado, a adaptação destes ambientes às necessidades particulares de novos contextos pode significar um aumento significativo ao potencial de inserção de novas formas de interação. 
Diante deste contexto, este trabalho buscouse tornar a interação com jogos em Ambiente Virtuais de Aprendizagem mais efetiva (AVA), a partir de mecanismos de percepção concebidos para representar aspectos da experiência do usuário com jogos de integrados a este tipo de ambiente.

\section{Inserção de games em ambientes virtuais de ensino}

Um dos nichos da Educação que vislumbra a inserção de jogos no processo de ensino e aprendizagem é a Educação à distância, porém, ao contrário do que se imaginava há anos atrás, hoje em dia ainda não comum à utilização. Na verdade, os jogos acabaram sendo mais utilizados apenas como forma de reforçar o conhecimento dos alunos. É pouco, se pensarmos no potencial que um jogo pode ter na área de educação. A possibilidade de simular diferentes situações, planejando, antecipando ações e criando estratégias para resolução dos problemas, constituem-se em característica fundamental para a construção e apropriação de conceitos, implicando o sujeito totalmente no processo de aprendizagem, levando-o a uma maior autonomia na escolha das suas ações (ALVES, 2008).

Para que a utilização dos jogos em ambientes virtuais de aprendizagem seja realmente significativa, é necessário que o ambiente possa reconhecer a interação que o aluno teve com a interface jogo, possibilitando assim uma percepção social da experiência do usuário entre os membros de um curso online, e para que isso ocorra é necessário que essa incorporação seja projetada dentro de princípios de design instrucional para a concepção e construção destes artefatos.

Essa necessidade de percepção que os alunos e professores têm em ter consciência das atividades do grupo, no presente, passado e futuro é um dos problemas que devem ser tratados na construção de cursos online, especificadamente com a utilização de jogos. A percepção é uma das características relevantes que devem ser incorporadas nas ferramentas de ensino, pois com seu uso é possível melhorar a eficácia do processo de colaboração, possibilitando aos indivíduos perceber o que o outro faz, e com isso, prover informações que estimulem a cooperação da melhor forma possível (LOBATO, GOMES, MONTEIRO, \& NIBON, 2007).

\section{Método}

Utilizamos a literatura de Interação Humano-computador, especificamente o método de design da interação (PREECE, SHARP, \& ROGERS, 2002). Essencialmente, o processo é composto por quatro atividades básicas Figura 1: (1) identificação das necessidades do usuário; (2) desenvolvimento de alternativas de design; (3) construção de versões iterativas e (4) avaliação do design.

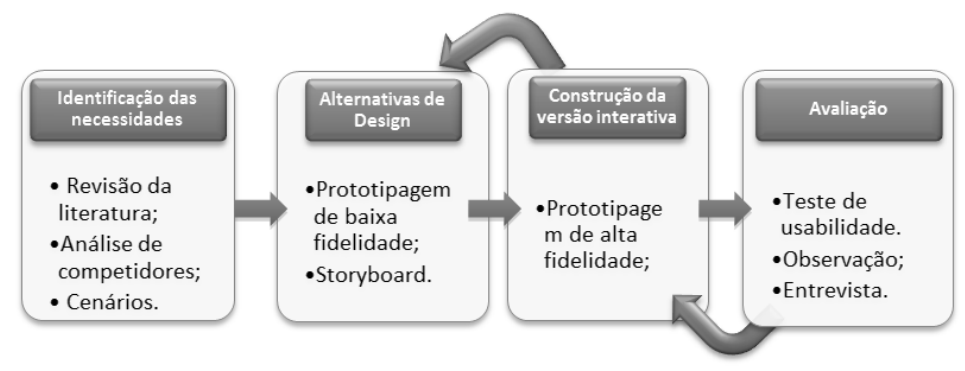

Figura 1. Processo de desenvolvimento 
Consideramos ainda três aspectos chaves do processo: foco no usuário, definição de metas de usabilidade e prototipagem evolutiva. Versões evolutivas do produto permitiram o refinamento baseado em resultados de avaliações de versões intermediárias. Com base nessas considerações, os procedimentos utilizados para atingir o método utilizado neste trabalho, compõem-se das ações descritas na seções seguintes.

- Identificação das necessidades: envolveu uma pesquisa da situação atual para identificar necessidades e oportunidades de melhoria;

- Alternativas de design: foi utilizado prototipagem de baixa fidelidade e storyboard;

- Construção da versão interativa: versão pôde ser testada pelos usuários.

- Testes de avaliação com usuário: foi realizado um teste usabilidade, através de observação.

\section{Resultados}

Nesta seção é descrito os resultados obtidos neste trabalho, como resultados obteve-se uma versão interativa do produto e por fim temos os resultados da avaliação com usuários.

\subsection{Versão desenvolvida integrada a plataforma de LMS}

Um dos requisitos mais importantes do trabalho foi à implementação do componente de percepção da interação do usuário com a atividade tipo jogo, como mostra a Figura 4. Neste componente, é possível o professor ver as variáveis do jogo tais como: nome do aluno que jogou, data de realização da atividade tipo jogo, tempo que passou fazendo a atividade, quantidade de fases concluídas e pontuação.
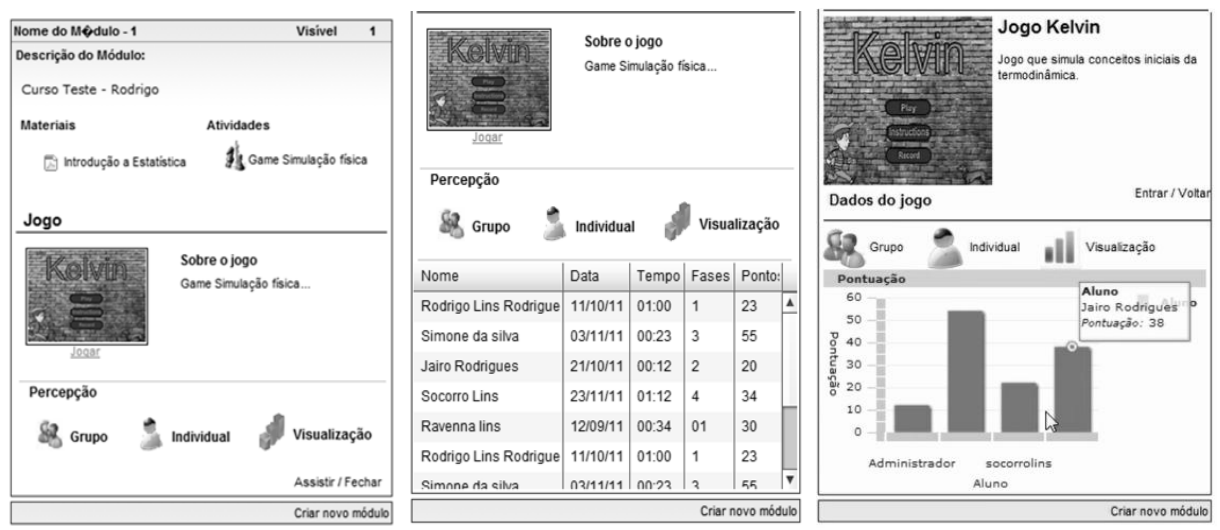

Figure 4. Telas de percepção da interação dos alunos

Outra opção no componente de visualização é o próprio aluno ao clicar em "Individual" ter a possibilidade de ver todo seu histórico de partidas ao longo do tempo. Na opção visualização é possível ambos (Aluno ou Professor) verem o desempenho geral do aluno em forma de gráficos de barras.

\subsection{Avaliação com usuários}

O teste com os usuários foi composto por um grupo de professores tutores de curso superior na modalidade à distância. Para a realização do teste, utilizamos duas ferramentas de coletas de dados: teste de usabilidade, através de observação. O grupo teve como atividades centrais do teste de usabilidade, o processo de inserção de um jogo na plataforma Amadeus, bem como a utilização das ferramentas de percepção. 

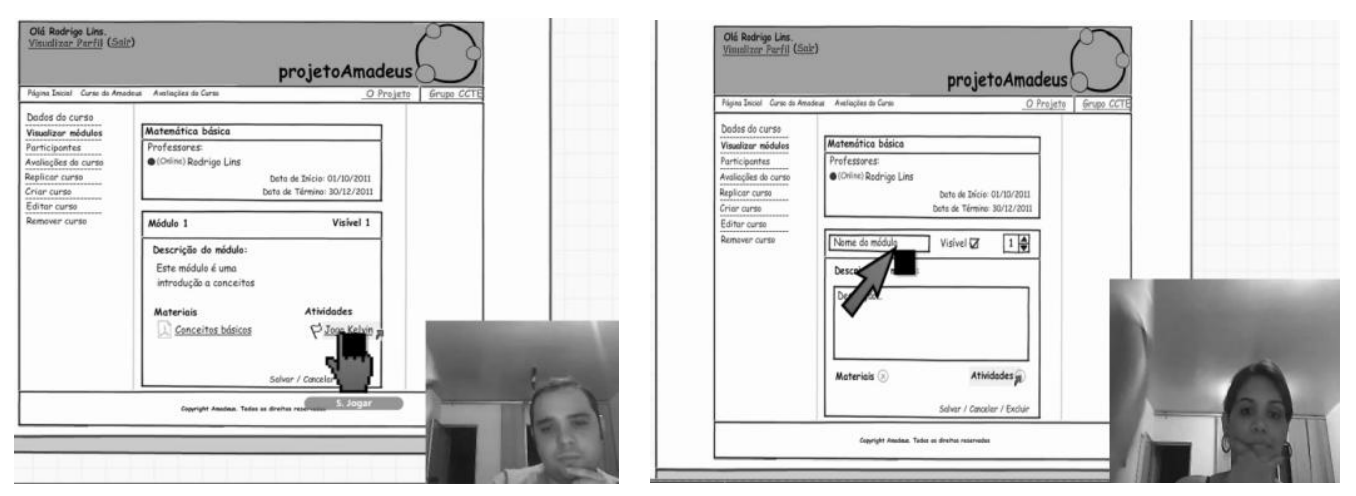

Figure 5. Teste de usabilidade

Durante as sessões de observações, foram coletados diferentes tipos de dados. Para cada tarefa, realizada por cada participante, foi possível medir: o grau de sucesso da execução, o total de erros cometidos, quantos erros de cada tipo ocorreram, quanto tempo foi necessário para concluí-la e o número de vezes que foi solicitado ajuda (Quadro 1).

Quadro 1: Resultado do teste de usabilidade

\begin{tabular}{|c|c|c|c|c|}
\hline Dado coletado & Usuário 1 & Usuário 2 & Usuário 3 & Usuário 4 \\
\hline Tempo necessário . & $6: 29 \min$ & $5: 30 \mathrm{~min}$ & $17: 25 \mathrm{~min}$ & $11: 00 \mathrm{~min}$ \\
\hline Fluxo de telas & $\begin{array}{l}\text { Não teve problema } \\
\text { com o fluxo de } \\
\text { interação. }\end{array}$ & $\begin{array}{l}\text { Não teve } \\
\text { problema com o } \\
\text { fluxo de } \\
\text { interação. }\end{array}$ & $\begin{array}{l}\text { Não teve } \\
\text { problema com o } \\
\text { fluxo de } \\
\text { interação. }\end{array}$ & $\begin{array}{l}\text { Não teve } \\
\text { problema com } \\
\text { o fluxo de } \\
\text { interação. }\end{array}$ \\
\hline $\begin{array}{l}\text { Grau de sucesso da } \\
\text { execução da tarefa } 1 \\
\text { (inserção do jogo). }\end{array}$ & $\begin{array}{l}\text { Conseguiu sucesso } \\
\text { na tarefa com } \\
\text { conceito (ótimo). }\end{array}$ & $\begin{array}{l}\text { Conseguiu } \\
\text { sucesso na tarefa } \\
\text { com conceito } \\
\text { (ótimo). }\end{array}$ & $\begin{array}{l}\text { Conseguiu } \\
\text { sucesso na tarefa } \\
\text { com uma dúvida } \\
\text { (Bom). }\end{array}$ & $\begin{array}{l}\text { Conseguiu } \\
\text { sucesso na } \\
\text { tarefa com } \\
\text { uma dúvida } \\
\text { (Bom). }\end{array}$ \\
\hline $\begin{array}{l}\text { Grau de sucesso da } \\
\text { tarefa } 2 \text { (Ferramentas } \\
\text { de percepção). }\end{array}$ & $\begin{array}{ll}\text { Não } & \text { conseguiu } \\
\text { sucesso } & \text { sem ajuda } \\
\text { (médio) } & \end{array}$ & $\begin{array}{l}\text { Não conseguiu } \\
\text { sucesso sem ajuda } \\
\text { (médio) }\end{array}$ & $\begin{array}{l}\text { Não conseguiu } \\
\text { sucesso sem ajuda } \\
\text { (médio) }\end{array}$ & $\begin{array}{l}\text { Não conseguiu } \\
\text { sucesso sem } \\
\text { ajuda (médio) }\end{array}$ \\
\hline $\begin{array}{l}\text { Total de erros } \\
\text { cometidos }\end{array}$ & $\begin{array}{ll}\text { Três erros } & \text { de } \\
\text { entendimento } & \text { de } \\
\text { componentes } & \text { de } \\
\text { interface. } & \end{array}$ & $\begin{array}{ll}\text { Dois erros } & \text { de } \\
\text { entendimento } & \text { de } \\
\text { componentes } & \text { de } \\
\text { interface. } & \end{array}$ & $\begin{array}{ll}\text { Quatro erros } & \text { de } \\
\text { entendimento } & \text { de } \\
\text { componentes } & \text { de } \\
\text { interface. } & \end{array}$ & $\begin{array}{l}\text { Dois erros de } \\
\text { entendimento } \\
\text { da interface. }\end{array}$ \\
\hline $\begin{array}{l}\text { Número de vezes que } \\
\text { foi solicitado ajuda. }\end{array}$ & $\begin{array}{l}\text { Quatro solicitações } \\
\text { para esclarecimento } \\
\text { do significado das } \\
\text { palavras } \\
\text { interface. }\end{array}$ & $\begin{array}{l}\text { Duas solicitações } \\
\text { para } \\
\text { esclarecimento da } \\
\text { funcionalidade da } \\
\text { ferramenta. }\end{array}$ & $\begin{array}{lr}\text { Seis vezes para } \\
\text { esclarecimento do } \\
\text { significado das } \\
\text { palavras na } \\
\text { interface. }\end{array}$ & $\begin{array}{l}\text { Duas } \\
\text { solicitações } \\
\text { para } \\
\text { esclarecimento } \\
\text { do significado } \\
\text { das palavras. }\end{array}$ \\
\hline
\end{tabular}

\section{Discussão dos resultados}

Através do teste de usabilidade realizado com o software concebido neste trabalho, pudemos analisar alguns fatores ergonômicos que contribuíram para a qualidade e bemestar no processo de inserção de games na plataforma Amadeus. Embora o artigo tivesse como foco abordar essencialmente o processo de concepção e desenvolvimento, o fator ergonômico acabou sendo identificado na fase de testes de usabilidade com o usuário. 
O teste de usabilidade foi composto de duas tarefas realizadas por quatro professores. Foi possível observar que o tempo médio para realização das tarefas foi de 10,36 minutos. Se comparado aos demais ambientes virtuais de aprendizagem disponibilizados no mercado, podemos considerar que esse tempo foi relativamente baixo. Em relação ao fluxo de interação identificado através da analise da tarefa, foi possível afirmar que não foi cometido erros pelo usuário em relação ao fluxo. Em relação à linguagem utilizada nos componentes de interface, tivemos em média 2,7 erros por usuário, o que implicou na modificação de diversos termos utilizados na ferramenta, essas modificações puderam ser testadas e validadas durante o refinamento dos protótipos.

\section{Considerações finais}

Este trabalho apresentou uma solução para o suporte a jogos, permitindo que professores e alunos possam perceber a interação do grupo na plataforma, tendo como objetivo conceber diferentes mecanismos de percepção para representar aspectos da experiência do usuário com jogos de simulação integrados a plataforma Amadeus Para atingir o objetivo proposto, utilizamos a literatura de Interação Humano-computador, especificamente o método de Design de interação. Como resultados deste trabalho, foi possível desenvolver uma interface que professores, sem muita experiência com ambientes virtuais de aprendizagem, possam utilizar jogos no processo de ensino e aprendizagem, possibilitando uma melhoria significativa, do ponto de vista da utilização de jogos, na plataforma, um modelo de desenvolvimento de componentes para plataformas do tipo AVA baseado em princípios e técnicas de IHC, para que outros trabalhos possam ser desenvolvidos baseados no método utilizado.

\section{Referencias}

Alves, L. e. (2008). Ensino On-Line, jogos eletrônicos e RPG: Construindo novas lógicas. Comunidades Virtuais.

Gee, J. (2007). Good video games and good learning: collected essays on video games, learning and literacy. Peter Lang, 30-44.

Lobato, L. L., Gome, A. S., Monteiro, B. S., \& NIBON, R. (2007). Aspectos de Percepção como Instrumento de Acompanhamento e de Avaliação em Ambientes Virtuais. XVIII Simpósio Brasileiro de Informática na Educação.

Oeiras, J. Y. (2002). Modalidades Síncronas de Comunicação e Elementos de Percepção em Ambientes de EaD. XXIII Simpósio Brasileiro de Informática na Educação, pp. 317326.

Preece, J., SHARP, H., \& ROGERS, Y. (2002). Interaction design: Beyond human-computer interaction. USA.

Prensky, M. (2007). Digital game-based learning: practical ideas for the application of digital game-based learning. Paragon House, 131-131.

Soares, J. (2001). Um Sistema de Gestão para a Educação Tecnológica à Distância: Projeto e Implementação. Universidade Federal do Ceará, Dissertação de mestrado.

Soares, J., Serra, A., Oliveira, A., \& Barroso, G. (2001). Análise das Dimensões Críticas da Educação à Distância como base para a Especificação de Um Sistema de Gestão. XXVII Seminário Integrado de Software e Hardware - SEMISH. 